\title{
Adsorption of small gas molecules on pure and Al-doped graphene sheet: a quantum mechanical study
}

\author{
DHARMVEER SINGH, ASHEESH KUMAR and DEVESH KUMAR* \\ Department of Applied Physics, School for Physical Sciences, Babasaheb Bhimrao Ambedkar University, Lucknow \\ 226025, India \\ *Author for correspondence (dkclcre@yahoo.com)
}

MS received 26 September 2016; accepted 13 February 2017; published online 3 October 2017

\begin{abstract}
The interaction of small gas molecules $\left(\mathrm{CCl}_{4}, \mathrm{CH}_{4}, \mathrm{NH}_{3}, \mathrm{CO}_{2}, \mathrm{~N}_{2}, \mathrm{CO}, \mathrm{NO}_{2}, \mathrm{CCl}_{2} \mathrm{~F}_{2}, \mathrm{SO}_{2}, \mathrm{CF}_{4}, \mathrm{H}_{2}\right)$ on pure and aluminium-doped graphene were investigated by using the density functional theory to explore their potential applications as sensors. It has been found that all gas molecules show much stronger adsorption on the Al-doped graphene than that of pure graphene (PG). The Al-doped graphene shows the highest adsorption energy with $\mathrm{NO}_{2}, \mathrm{NH}_{3}$ and $\mathrm{CO}_{2}$ molecules, whereas the PG binds strongly with $\mathrm{NO}_{2}$. Therefore, the strong interactions between the adsorbed gas molecules and the Al-doped graphene induce dramatic changes to graphene's electronic properties. These results reveal that the sensitivity of graphene-based gas sensor could be drastically improved by introducing the appropriate dopant or defect. It also carried out the highest occupied molecular orbital-lowest unoccupied molecular orbital energy gap of the complex molecular structure that has been explored by M06/6-31++G** method. These results indicate that the energy gap fine tuning of the pure and Al-doped graphene can be affected through the binding of small gas molecules.
\end{abstract}

Keywords. DFT; small gas molecules; graphene; aluminium-doping; non-covalent interaction; grapheme-based gas sensors.

\section{Introduction}

Carbon is the versatile element on the earth's crust and it is found on the earth's surface in different allotropes as graphite, diamonds, charcoal and coke, respectively. The newer allotropes of carbon were discovered such as graphene, carbon nanotubes (CNTs) and fullerenes [1-3]. Graphene is the youngest known allotrope of carbon, which is a twodimensional and one-atom thick material consisting of $\mathrm{sp}^{2}$ hybridized carbon atoms arranged in a honeycomb structure. These allotropes of carbon are extensively used in research, that is, from biomedical to environment applications due to their unique physical and chemical properties [4]. The exceptional properties of carbon nano materials, such as electronic, thermal, optical, mechanical and transport properties make them promising candidates for various potential applications [5-7]. From several experimental and theoretical studies it is observed that the transport and electronic properties are extremely sensitive to change in the local chemical environment [8-10]. Carbon nanostructures (CNSs) exhibit non-covalent interaction such as the $\mathrm{XH}-\pi$, cation $-\pi$, anion$\pi$ and $\pi-\pi$ interaction towards the small gas molecules, metal ions and bio molecules [11-15]. The XH- $\pi$ weak interactions were extensively studied in recent years [16-20]. These interactions have been considered to be a unique type of hydrogen bonding interaction in which $\pi$ electron acts as the proton acceptor [14]. Graphene is a sensitive nano material, which detects all the individual events when a gas molecule is adsorbed to or de-adsorbed from its surface [21]. However, it is very difficult to prepare a perfect single layer graphene with zero band gap. Doping is one of the most efficient method to improve the electronic properties of the materials. Wang et al have found that the $\mathrm{sp}^{2}$ hybridization is affected and it changes the electronic properties of the system when $\mathrm{B}, \mathrm{N}$ and B-N are doped with pure graphene (PG) [22]. Lherbier et al showed that the charge mobility and conductivity of graphene changes when $\mathrm{B} / \mathrm{N}$ impurity atom is added to its surface [23]. Recently, there are several experimental studies on $\mathrm{Al}, \mathrm{Ga}$ and Pd-doped graphene sheet-based gas sensor [24,25]. Interestingly, the nanoparticles such as $\mathrm{Al}, \mathrm{Ga}$ and Pd incorporated the significant changes in the sensitivity and selectivity towards the gas molecules. The structure and physical properties of CNSs make them potential candidates as sensors to detect different types of gas molecules. Dai and co-workers were the first to report the gas sensors based on CNTs to detect gas molecules such as $\mathrm{NO}_{2}$ and $\mathrm{NH}_{3}$ [26]. Recently, Schedin et al experimentally reported that graphene-based gas sensors possess very high sensitivity such that the adsorption of individual gas molecules could be detected [21]. CNSs can absorb a number of species such as gas molecule, metal ions, polymers, organic molecules and biomolecules such as proteins, nucleobases and deoxyribonucleic acid (DNA) on their surface and these adsorption properties provide opportunities for potential industrial applications [27-30]. 
Roman et al studied the adsorption of few amino acids on a single-walled CNT by using the DFT method [31]. CNTs have also been found to be suitable candidates for the negative electrode of the Li-ion batteries, where the $\mathrm{Li}$ diffuse between the positive and negative in the ionic state $[32,33]$. Thus, the fundamental understanding of the interaction of metals with CNTs in the ionic state is important. It is also important to know the role of various factors such as solvent and other chemical environments, which influence such cation- $\pi$ interaction [34-36]. Umadevi et al have found that the charge transfer between graphane and the molecules is an important factor in determining the binding strength of the complex molecular systems [37]. Zhang et al studied that doped graphane strongly interacts with $\mathrm{CO}, \mathrm{NO}$ and $\mathrm{NO}_{2}$ while $\mathrm{NH}_{3}$ interacts weakly [38]. Zou et al found that the $\mathrm{SiG}$ has higher chemical reactions towards the gas molecules due to doping of silicon atom and shows the higher adsorption energy with $\mathrm{CO}, \mathrm{O}_{2}, \mathrm{NO}_{2}$ and $\mathrm{H}_{2} \mathrm{O}$ [39]. In the current study, the Aldoped graphene was theoretically investigated to improve its gas sensing efficiency and selectivity towards the various gas molecules. The gas molecule $\mathrm{CCl}_{4}, \mathrm{CH}_{4}, \mathrm{NH}_{3}$, $\mathrm{CO}_{2}, \mathrm{CO}, \mathrm{NO}_{2}, \mathrm{CCl}_{2} \mathrm{~F}_{2}, \mathrm{SO}_{2}, \mathrm{CF}_{4}$ and $\mathrm{N}_{2} \mathrm{O}$, are all of great practical interest for industrial, environmental and medical applications. On the other hand, the effect of doping of the graphene sheet on the binding strength has been estimated. The charge transfer that occurred during the complex formation has also been explored. The change in the highest occupied molecular orbital-lowest unoccupied molecular orbital (HOMO-LUMO) energy gap of PG and Al-doped graphene upon the binding of these gas molecules has also been estimated.

\section{Computational methods}

The calculations of the interaction between PG, Al-doped graphene and gas molecule is carried out using the density functional theory. The geometrical calculations of all structures have been done by using one method B3LYP/6-31G* [40,41]. Initially, the individual gas molecule is adsorbed on the surface of PG and Al-doped graphene thereafter. Geometry optimization calculations were accomplished using Gaussian09 suite program [42]. It is important to note that complete geometrical configuration was tested but those shown are the lowest energy species feasible for the interaction of the compounds. Single point energy has been done at the M06/6-31++G** level to fine-tune the energy [43-46].

The adsorption energy $\left(E_{\mathrm{ad}}\right)$ of the small gas molecule (X $=\mathrm{CCl}_{4}, \mathrm{CH}_{4}, \mathrm{NH}_{3}, \mathrm{CO}_{2}, \mathrm{~N}_{2}, \mathrm{CO}, \mathrm{NO}_{2}, \mathrm{CCl}_{2} \mathrm{~F}_{2}, \mathrm{SO}_{2}$, $\mathrm{CF}_{4}, \mathrm{H}_{2}$ ) on the pure and $\mathrm{Al}$-doped graphene is calculated by the following equation (1).

$$
\begin{aligned}
E_{\text {ad }}= & E_{\text {graphene_X/graphene@Al_X }} \\
& -\left(E_{\text {graphene } / \mathrm{Al} @ \text { graphene }}+E_{\mathrm{X}}\right)
\end{aligned}
$$

Here, $E_{\text {graphene_X/graphene@Al_x }}$ represents the total energy of a

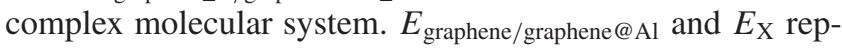
resent the total energies of the graphene and gas molecule, respectively. The individual small gas molecule was placed parallel to the surface of graphene and doped graphene at the $3 \AA$ distance. The variation of the charge on gas molecules as well as on pure and doped graphene when the individual gas molecules are kept at the $3 \AA$ distance from its surface was calculated. The charge transfer has been considered as the sum of all atoms in the pure and Al-doped graphene model system. Positive charge transfer values indicate the transfer of charge from graphene to the molecules, while negative charge values indicate the transfer of charge from the molecules to the pure and Al-doped graphene. The HOMO-LUMO energy gap of pure and Al-doped graphene as well as their complexes at M06/6-31++G** level of theory were also calculated. All calculations were carried out using the Gaussian09 program package.

\section{Results and discussion}

The optimized structure of pure and Al-doped graphene and their complexes with small molecules are shown in figures 1,2 and 3. The initial configuration of all small gaseous molecules were assigned so that these are oriented exactly parallel to the pure and Al-doped graphene at $3 \AA$ from its surface. In this paper, pure and Al-doped graphene was considered to study the interaction of small gas molecules with $\mathrm{X}-\pi$ non-covalent interaction towards carbon nano materials. Tables 1 and 2 summarize our results on the adsorption energy, equilibrium graphene-molecule distance $(\mathrm{d}$, defined as the distance of nearest atoms between graphene and molecule), the charge transfer $(\mathrm{Q}$, mulliken charge) and HOMO-LUMO energy gap for the most stable configurations of pure and Al-doped graphene adsorbed with various gas molecules in our calculations as shown in figures 2, 3 and tables 1, 2 . Subsequently, we look at the binding of the pure and Aldoped graphene with various gas molecules and the trend in the charge transfer. The HOMO-LUMO energy gap of pure and Al-doped graphene with adsorption of various gas molecules were also investigated. When one impurity atom as $\mathrm{Al}$ is substituted for one $\mathrm{C}$ atom in graphene sheet, the optimized configuration of the graphene sheet is dramatically distorted. The Al atom introduces the deformation of the sixmembered ring (6MR) near the doping site to relieve stress, as a result the $\mathrm{Al}$ atom protrudes out of the graphene sheet. The optimized carbon-dopant atom distance (Al-C) is 1.751 $\AA$ at B3YP/6-31G*, which is in agreement with the previous study [47].

\subsection{Adsorption energy and charge transfer}

The small gas molecules form $\mathrm{X}-\pi$ type complex with the pure and Al-doped graphene that are shown in figures 2 and 3. We observed the adsorption energy of small gas 


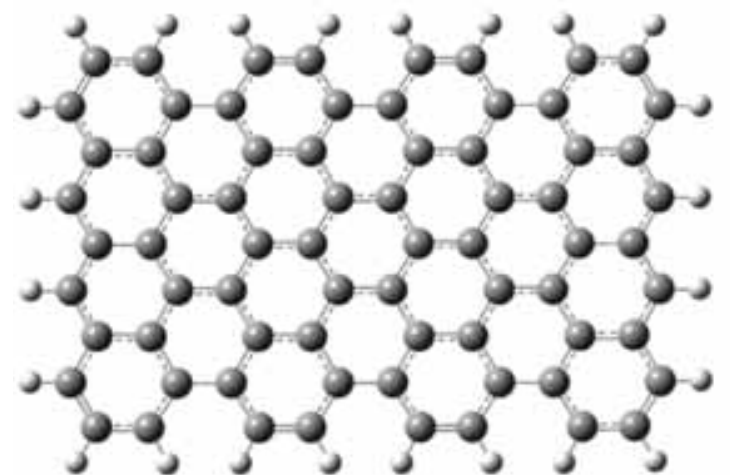

Graphene

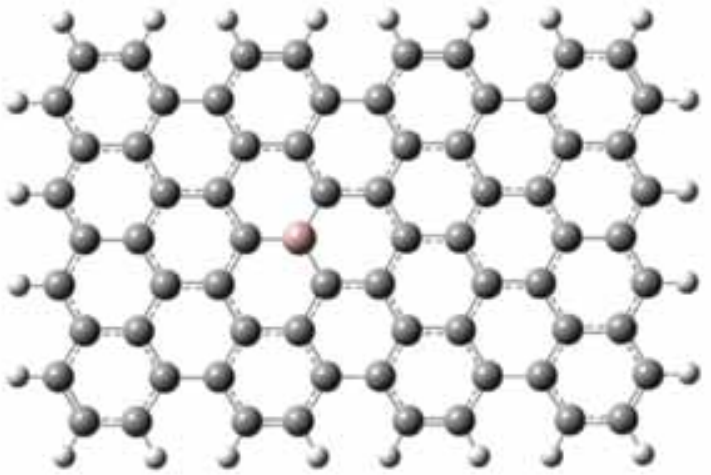

Graphene@Al

Figure 1. Top view of the optimized structure of pure and Al-doped graphene model system considered in this study.

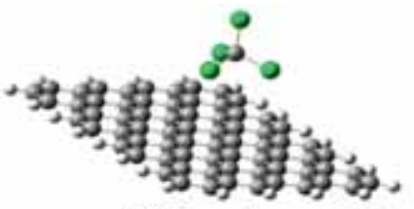

(a) Graphene_CCl

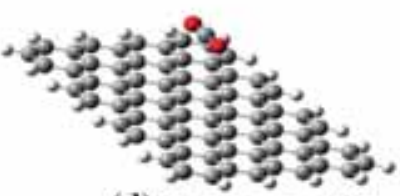

(d) Graphene_ $\mathrm{CO}_{2}$

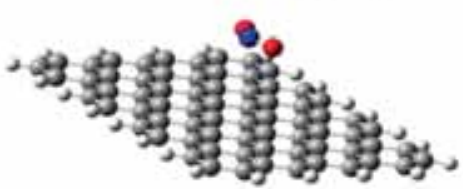

(g) Graphene_ $\mathrm{NO}_{2}$

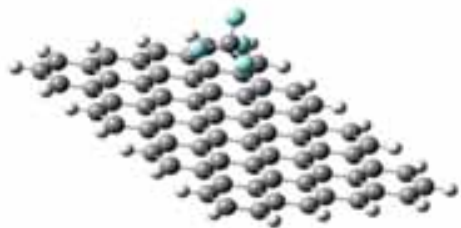

(j) Graphene_CF

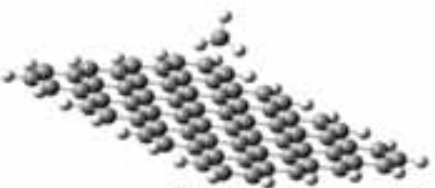

(b) Graphene_CH

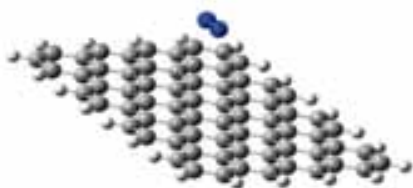

(e) Graphene_ $\mathrm{N}_{2}$

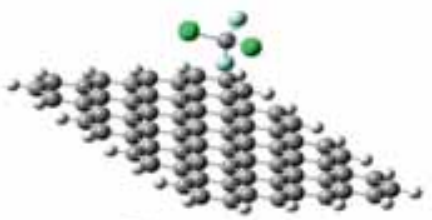

(h) Graphene_CCl${ }_{2} \mathrm{~F}_{2}$

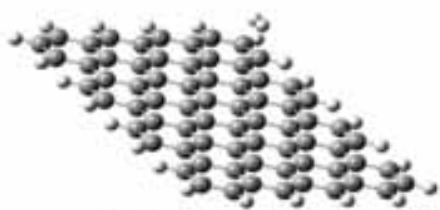

(k) Graphene $\mathrm{H}_{2}$

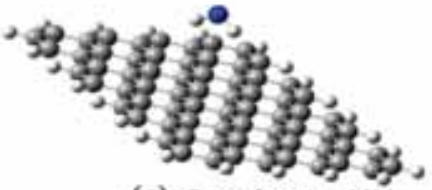

(c) Graphene $\mathrm{NH}_{3}$

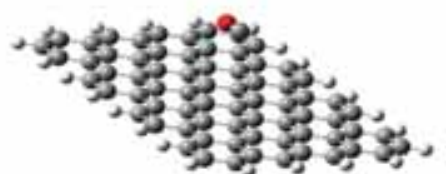

(f) Graphene_CO

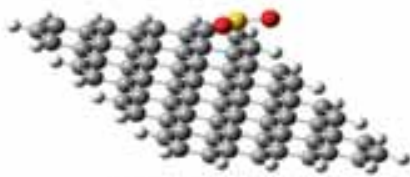

(i) Graphene_SO

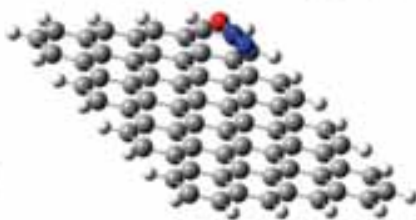

(I) Graphene $\mathrm{N}_{2} \mathrm{O}$

Figure 2. Optimized geometries of pure graphene with small gas molecule adsorbed (a) $\mathrm{CCl}_{4}$, (b) $\mathrm{CH}_{4},(\mathbf{c}) \mathrm{NH}_{3}$, (d) $\mathrm{CO}_{2}$, (e) $\mathrm{N}_{2}$, (f) $\mathrm{CO}$, (g) $\mathrm{NO}_{2}$, (h) $\mathrm{CCl}_{2} \mathrm{~F}_{2}$, (i) $\mathrm{SO}_{2}$, (j) $\mathrm{CF}_{4}$, (k) $\mathrm{H}_{2}$ and (l) $\mathrm{N}_{2} \mathrm{O}$ by M06/6-31++G** method.

molecule complexes with pure and Al-doped graphene when the gas molecules are kept parallel to the graphene surface at $3 \AA$ distance. Tables 1, 2 and figure 4 display the adsorption energy, charge transfer and molecule sheet distance of the small gas molecule complexes with pure and Al-doped graphene at M06/6-31++g** level of theory.

Interestingly, a different trend in the case of small gas molecule interacting with pure and Al-doped graphene is observed, the adsorption energy of small gas molecules towards the Al-doped graphene is greater than PG. From table 2 and figure 2, the adsorption energy of all gas molecules is higher for the Al-doped graphene than that of PG.

For $\mathrm{CCl}_{4}$ and $\mathrm{CH}_{4}$ adsorbed on $\mathrm{PG}$, the most energetically favourable configuration (Graphene_ $\mathrm{CCl}_{4}$ ) is also identical. The adsorption of $\mathrm{CCl}_{4}$ and $\mathrm{CH}_{4}$ on $\mathrm{PG}$ is non-covalent interaction with the adsorption energy of -0.394 and 


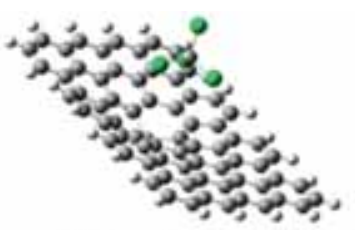

(a) Graphene@AI_CCl 4

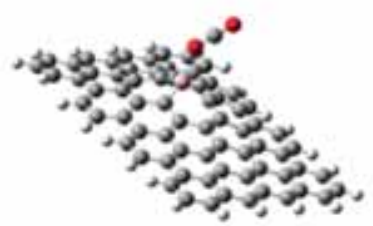

(d)Graphene@Al_CO

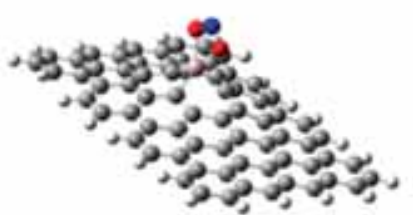

(g) Graphene@Al_NO

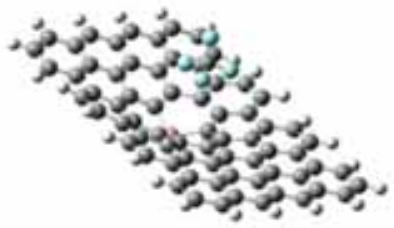

(j) Graphene@Al_CF

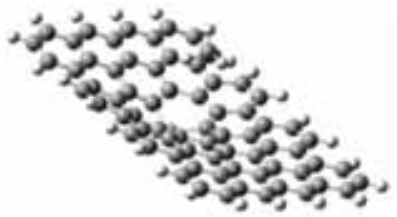

(b) Graphene@AI_CH

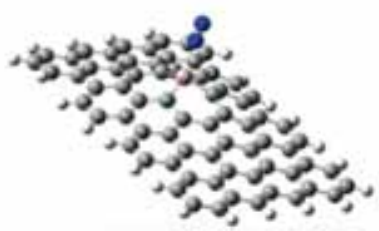

(e) Graphene@Al_ $\mathrm{N}_{2}$

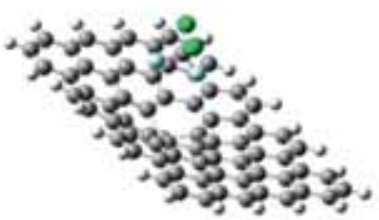

(h) Graphene@Al_CCl${ }_{2} \mathrm{~F}_{2}$

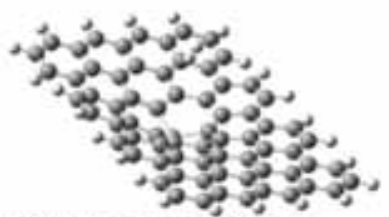

(k) Graphene@Al_H

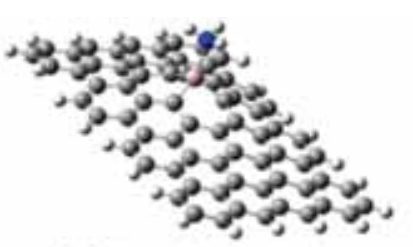

(c) Graphene@Al_NH

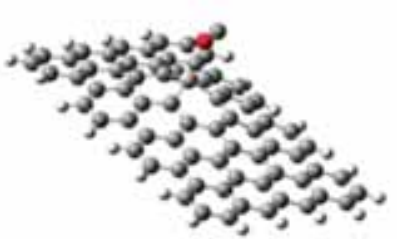

(f) Graphene@Al_CO

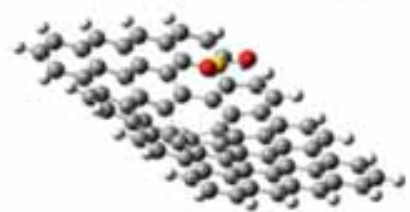

(i) Graphene@Al_SO

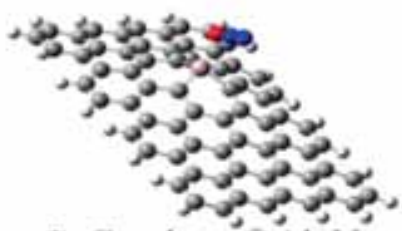

(I) Graphene $a$ Al_ $\mathrm{N}_{2} \mathrm{O}$

Figure 3. Optimized geometries of aluminium-doped graphene (@ $\mathrm{Al}$ shown as $\mathrm{Al}$ doping in pure graphene) adsorbed with small gas molecules (a) $\mathrm{CCl}_{4}$, (b) $\mathrm{CH}_{4}$, (c) $\mathrm{NH}_{3}$, (d) $\mathrm{CO}_{2}$, (e) $\mathrm{N}_{2}$, (f) $\mathrm{CO}$, (g) $\mathrm{NO}_{2}$, (h) $\mathrm{CCl}_{2} \mathrm{~F}_{2}$, (i) $\mathrm{SO}_{2}$, (j) $\mathrm{CF}_{4}$, (k) $\mathrm{H}_{2}$ and (l) $\mathrm{N}_{2} \mathrm{O}$ by M06/6-31++G** method.

Table 1. The adsorption energy (eV), molecule sheet distance $(\AA)$, charge transfer (a.u.) and HOMOLUMO energy gap (eV) at M06/6-31++G** level of theory.

\begin{tabular}{lccccc}
\hline $\begin{array}{l}\text { Carbon } \\
\text { nanomaterial }\end{array}$ & $\begin{array}{c}\text { Small gas } \\
\text { molecule }\end{array}$ & $\begin{array}{c}\text { Adsorption } \\
\text { energy (eV) }\end{array}$ & $\begin{array}{c}\text { Molecule sheet } \\
\text { distance }(\AA)\end{array}$ & $\begin{array}{c}\text { Charge on gas } \\
\text { molecule (a.u.) }\end{array}$ & $\begin{array}{c}\text { HOMO-LUMO } \\
\text { gap (eV) }\end{array}$ \\
\hline \multirow{4}{*}{ Graphene } & $\mathrm{CCl}_{4}$ & -0.394 & 4.498 & -0.0196 & 0.3339 \\
& $\mathrm{CH}_{4}$ & -0.067 & 3.784 & -0.0133 & 0.3336 \\
& $\mathrm{NH}_{3}$ & -0.145 & 3.357 & 0.0334 & 0.3336 \\
& $\mathrm{CO}_{2}$ & -0.122 & 3.626 & 0.0169 & 0.3336 \\
& $\mathrm{~N}_{2}$ & -0.083 & 3.828 & 0.014 & 0.3339 \\
$\mathrm{CO}$ & -0.110 & 3.732 & 0.0098 & 0.3336 \\
& $\mathrm{NO}_{2}$ & -0.996 & 3.573 & 0.025 & 0.8727 \\
& $\mathrm{CCl}_{2} \mathrm{~F}_{2}$ & -0.119 & 3.355 & 0.0039 & 0.3336 \\
$\mathrm{SO}_{2}$ & -0.279 & 3.578 & 0.0254 & 0.3339 \\
& $\mathrm{CF}_{4}$ & -0.150 & 3.404 & 0.0552 & 0.3336 \\
& $\mathrm{H}_{2}$ & -0.013 & 4.946 & 0.0006 & 0.3339 \\
& $\mathrm{~N}_{2} \mathrm{O}$ & -0.123 & 3.634 & 0.0180 & 0.3340 \\
\hline
\end{tabular}

$-0.067 \mathrm{eV}$ and the molecule sheet distance of 4.498 and $3.784 \AA$, respectively. The charge transfer from graphene to $\mathrm{CCl}_{4}$ and $\mathrm{CH}_{4}$ molecule is -0.0196 and -0.0133 a.u., which indicates that the PG acts as a donor, and the gas molecule acts as an acceptor. Therefore, $\mathrm{PG}$ is less sensitive to the $\mathrm{CCl}_{4}$ than $\mathrm{CH}_{4}$ molecule. The most stable configuration of $\mathrm{CCl}_{4}$ 
Table 2. The adsorption energy (eV), molecule sheet distance $(\AA)$, charge transfer (a.u.) and HOMOLUMO energy gap $(\mathrm{eV})$ at M06/6-31++G** level of theory.

\begin{tabular}{lccccc}
\hline $\begin{array}{l}\text { Carbon } \\
\text { nanomaterial }\end{array}$ & $\begin{array}{c}\text { Small gas } \\
\text { molecule }\end{array}$ & $\begin{array}{c}\text { Adsorption } \\
\text { energy (eV) }\end{array}$ & $\begin{array}{c}\text { Molecule sheet } \\
\text { distance }(\AA)\end{array}$ & $\begin{array}{c}\text { Charge on gas } \\
\text { molecule (a.u.) }\end{array}$ & $\begin{array}{c}\text { HOMO-LUMO } \\
\text { gap (eV) }\end{array}$ \\
\hline Graphene@ Al & $\mathrm{CCl}_{4}$ & -1.354 & 3.920 & -0.007 & 0.661 \\
& $\mathrm{CH}_{4}$ & -1.242 & 4.300 & 0.004 & 0.616 \\
& $\mathrm{NH}_{3}$ & -2.948 & 2.053 & 0.493 & 1.080 \\
$\mathrm{CO}_{2}$ & -2.019 & 2.158 & 0.423 & 1.574 \\
& $\mathrm{~N}_{2}$ & -1.279 & 2.210 & 0.837 & 0.444 \\
$\mathrm{CO}$ & -1.255 & 2.344 & 0.276 & 0.494 \\
& $\mathrm{NO}_{2}$ & -3.867 & 1.894 & -0.065 & 0.330 \\
$\mathrm{CCl}_{2} \mathrm{~F}_{2}$ & -1.361 & 3.956 & 0.020 & 0.579 \\
& $\mathrm{SO}_{2}$ & -1.608 & 3.579 & 0.045 & 0.599 \\
$\mathrm{CF}_{4}$ & -1.354 & 3.920 & 0.138 & 0.662 \\
& $\mathrm{H}_{2}$ & -1.637 & 6.306 & 0.001 & 1.512 \\
& $\mathrm{~N}_{2} \mathrm{O}$ & -1.409 & 2.163 & 0.518 & 0.453 \\
\hline
\end{tabular}

and $\mathrm{CH}_{4}$ on graphene@ $\mathrm{Al}$ is a configuration with the $\mathrm{CCl}_{4}$ and $\mathrm{CH}_{4}$ molecule parallel to the graphene sheet and $\mathrm{Cl}$ atom of $\mathrm{CCl}_{4}$ and $\mathrm{H}$ atom of $\mathrm{CH}_{4}$ adsorbed on the top of $\mathrm{Al}$ atom, which is shown in figure $3 \mathrm{a}$ and $\mathrm{b}$, where the molecular sheet distance is 3.920 and $4.300 \AA$, respectively. The calculated $E_{\text {ad }}$ value is -1.354 and $-1.242 \mathrm{eV}$, which indicates that the graphene@Al has higher adsorption enegy than $\mathrm{PG}$ with $\mathrm{CCl}_{4}$ and $\mathrm{CH}_{4}$.

The $\mathrm{NH}_{3}$ molecule shows different adsorption configurations on pure and $\mathrm{Al}$-doped graphene, showing a more complicated adsorption mechanism than the other molecules. On the PG, the configuration with the three hydrogen atoms of $\mathrm{NH}_{3}$ pointing towards the graphene plane is the favourable one (figure $3 \mathrm{c}$ ), which gives an adsorption energy and molecule distance of $-0.145 \mathrm{eV}$ and $3.357 \AA$, respectively. This result is consistent with previous reports about $\mathrm{NH}_{3}$ adsorbed on CNTs $(-0.14 \mathrm{eV})$ and $\mathrm{NH}_{3}$ adsorbed on graphene $(0 \sim-0.17 \mathrm{eV})[48,49]$, which indicates a weak interaction between $\mathrm{NH}_{3}$ and the PG. On the Aldoped graphene, $\mathrm{NH}_{3}$ is attached to the $\mathrm{Al}$ atom with the $\mathrm{N}$ atom pointing at the sheet, which gives an adsorption energy of $-2.948 \mathrm{eV}$ and an $\mathrm{Al}-\mathrm{N}$ distance of $2.053 \AA$ (as shown in figure $3 \mathrm{c}$ and table 2). The charge transfer from $\mathrm{NH}_{3}$ to graphene is 0.493 a.u., which indicates that the graphene behaves as charge acceptor and $\mathrm{NH}_{3}$ molecule as charge donor. The adsorption energy of $\mathrm{NH}_{3}$ on Algraphene $(-2.948 \mathrm{eV})$ is much higher than that on the PG, which attributes to the strong interaction between the electron-deficient $\mathrm{Al}$ atom and the electron-donating $\mathrm{N}$ atom of $\mathrm{NH}_{3}$. It is also investigated that the Al-doped graphene undergoes an obvious distortion upon $\mathrm{NH}_{3}$ adsorption (figure $3 \mathrm{c}$ ), indicating that the $\mathrm{B}$ site is transformed from $\mathrm{sp}^{2}$ to $\mathrm{sp}^{3}$ hybridization, which matched the previous study [35]. The molecular distance between $\mathrm{Al}$ and $\mathrm{N}$ is $2.053 \AA$ A. This strong interaction is also evident in the electronic total charge density on Al-doped graphene system, which shows large electron density overlap.
The adsorption energy of this complex system is $-0.122 \mathrm{eV}$ and molecule-sheet distance is $3.626 \AA$, which are shown in table 1 and figure $2 \mathrm{~d}$. The low adsorption energy and long molecule sheet distance indicate a weak interaction. When the $\mathrm{CO}_{2}$ molecule is adsorbed on PG, the calculated charge transfer of $\mathrm{CO}_{2}$ is 0.0169 a.u. In this configuration, the $\mathrm{CO}_{2}$ molecule acts as a charge donor. When the $\mathrm{CO}_{2}$ molecule is adsorbed on Al-doped graphene, one oxygen atom of $\mathrm{CO}_{2}$ shows most stable configuration towards the $\mathrm{Al}$ atom of graphene@ $\mathrm{Al}$ sheet. In this configuration, the adsorption energy and molecule sheet distance $(\mathrm{O}-\mathrm{Al})$ is $-2.019 \mathrm{eV}$ and $2.158 \AA$, respectively. This result indicates that the interaction of $\mathrm{CO}_{2}$ with graphene@ $\mathrm{Al}$ is much stronger than that of $\mathrm{PG}$ due to large transfer of charge. In this configuration, the charge transfer from $\mathrm{CO}_{2}$ to the graphene@ $\mathrm{Al}$ is 0.423 a.u., which means that the $\mathrm{CO}_{2}$ molecule acts as a charge donor and graphene@ $\mathrm{Al}$ acts as a charge acceptor.

In case of graphene_ $\mathrm{N}_{2}$ configuration, the $\mathrm{N}-\mathrm{N}$ axis gets aligned parallel to the graphene plane along the axis of two opposite $\mathrm{C}$ atoms of the $6 \mathrm{MR}$, which was found to be the most stable configuration. The adsorption energy and the molecule sheet distance of this complex system is $-0.083 \mathrm{eV}$ and $3.828 \AA$ A respectively as shown in figure $4 \mathrm{a}$, c and table 1 . The charge transfer between $\mathrm{N}_{2}$ and graphene was calculated from Mulliken population analysis, which is shown in table 1. This result indicates that the interaction is weak in nature due to very small adsorption energy and charge transfer. When adsorbed on Al-doped graphene (graphene@Al), $\mathrm{N}_{2}$ adopts perpendicular oreintation with $\mathrm{Al}$ atom of the graphene sheet. In this configuration, the one $\mathrm{N}$ atom of $\mathrm{N}_{2}$ and $\mathrm{Al}$ atom of graphene@ $\mathrm{Al}$ is very close as shown in figure 3e. The adsorption energy and the molecule sheet distance is $-1.279 \mathrm{eV}$ and $2.210 \AA$, respectively (as shown in figures $4 \mathrm{a}$ and c). The charge transfer from $\mathrm{N}_{2}$ to graphene@ $\mathrm{Al}$ is 0.837 a.u., which indicates that $\mathrm{N}_{2}$ acts as a charge donor. In this configuration, the adsorption energy of the complex system is higher than 
(a)

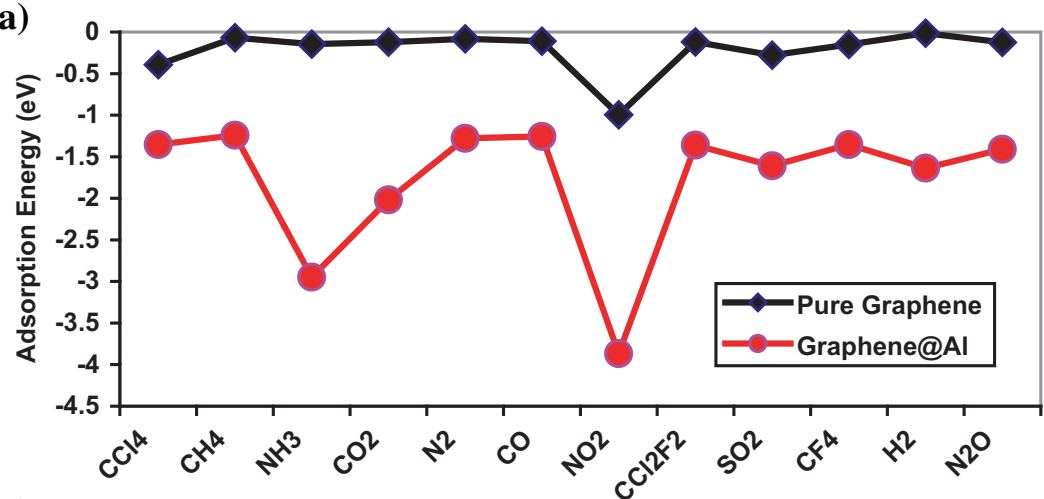

(b)

Small gas molecules

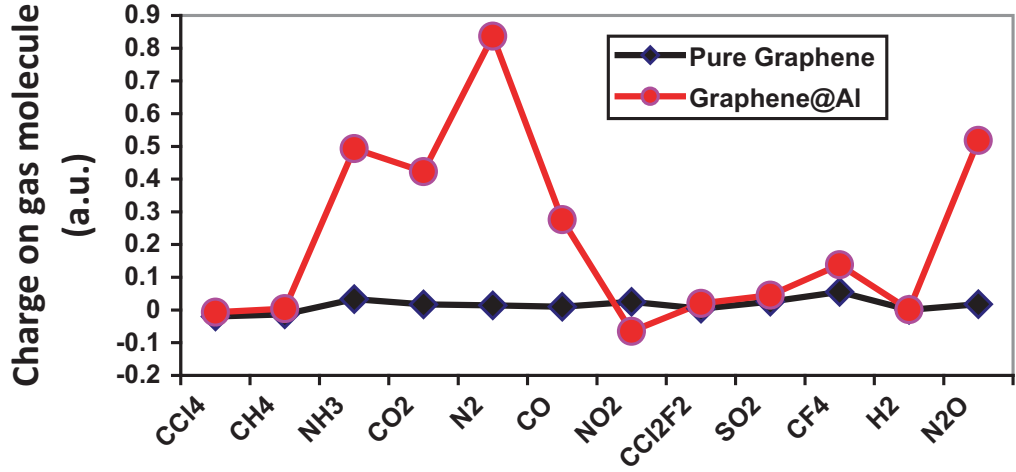

(c)

Small gas molecules

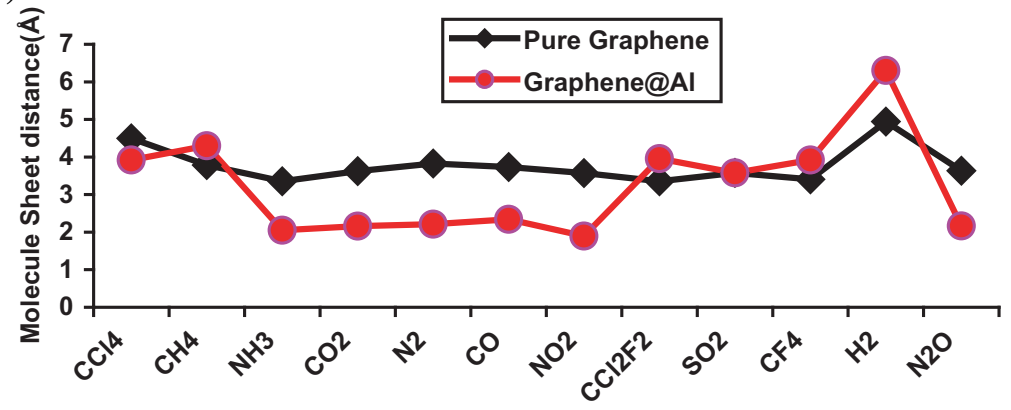

(d)

Small gas molecules

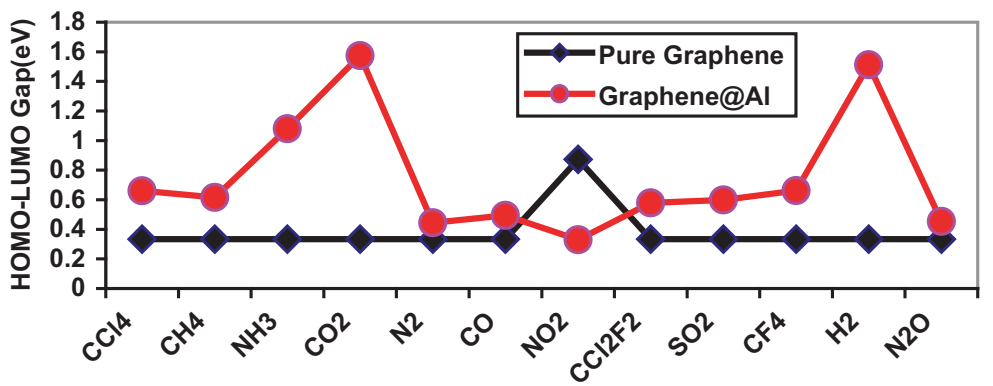

Small Gas molecule

Figure 4. (a) The adsorption energy $E_{\text {ad }}$, (b) charge transfer, (c) molecule sheet distance and (d) HOMO-LUMO energy gap of small gas molecules with pure and Al-doped graphene complexes at the M06/-31++G** level of theory. The red line with solid red circles represents the variation for the aluminium-doped graphene whereas the black line with black solid squares represent the variation for pure graphene. The HOMOLUMO gap for pure graphene is $0.33 \mathrm{eV}$ and for Al-doped graphene is $0.22 \mathrm{eV}$ without any gas molecules. 
the graphene_ $\mathrm{N}_{2}$ due to large transfer of charge, which are responsible for strong interaction.

The most stable configuration of CO molecule is similar to the $\mathrm{CO}_{2}$ and $\mathrm{N}_{2}$, which are aligned parallel to the PG plane along the axis of two opposite $\mathrm{C}$ atoms of the $6 \mathrm{MR}$ in the complex molecular structure. The adsorption energy and molecule sheet distance is $-0.110 \mathrm{eV}$ and $3.732 \AA$, respectively (as shown in table 1). When the $\mathrm{CO}$ molecule is adsorbed on $\mathrm{PG}$, the charge calculated on the $\mathrm{C}$ and $\mathrm{O}$ atoms of the $\mathrm{CO}$ molecule are 0.100 and -0.090 a.u., respectively, while there is no charge on the carbon atoms of the PG. Therefore, we can say that a very small charge is transferred from CO to the PG. The low adsorption energy and very small charge transfer indicates weak physisorption. When the $\mathrm{CO}$ molecule is adsorbed on Al-doped graphene, $\mathrm{CO}$ molecule adopts a tilted oreintation with respect to the plane of the Al-containig 6MR, with the $\mathrm{O}$ atom close to graphene@ Al. In this complex structure, the adsorbed energy and molecule sheet distance are found be $-1.255 \mathrm{eV}$ and $2.344 \AA$, respectively. The charge transfer from CO molecule to graphene@ Al is 0.275 a.u. In this configuration, the adsorption energy of graphene@ $\mathrm{Al} \_\mathrm{CO}$ is higher than graphene_CO complex (as shown in table 2 and figure 4a).

The adsorption energy and shortest distance from $\mathrm{PG}$ to the nearest $\mathrm{O}$ atom of $\mathrm{NO}_{2}$ are $-0.996 \mathrm{eV}$ and $3.573 \AA$, respectively, which indicates a weak interaction between the $\mathrm{NO}_{2}$ and PG. However, the adsorption energy of $\mathrm{NO}_{2}$ on PG can remarkably change the electronic properties of $\mathrm{PG}$ and the charge transferred from $\mathrm{NO}_{2}$ to PG is about 0.02504 a.u. It is clear that PG behaves as charge acceptor. In other words, $\mathrm{PG}$ is more sensitive to the $\mathrm{NO}_{2}$ molecule than any other gas molecule. For $\mathrm{NO}_{2}$ adsorbed on AlG (Al-doped graphene), the most stable configuration (Graphene@Al_NO $\mathrm{NO}_{2}$ ) is similar to that of graphene_ $\mathrm{NO}_{2}$. However, the oxygen atom of $\mathrm{NO}_{2}$ is bonded to the $\mathrm{AlG}$ as shown in figure $2 \mathrm{~g}$. The $\mathrm{O}-$ $\mathrm{Al}$ bond length is $1.894 \AA$ and the adsorption energy for Graphene@Al_ $\mathrm{NO}_{2}$ is $-3.867 \mathrm{eV}$, which indicates that $\mathrm{NO}_{2}$ is chemisorbed on the graphene@Al. In this configuration, the adsorption energy is greater than graphene_NO $\mathrm{NO}_{2}$ due to large charge transferred from graphene@Al to $\mathrm{NO}_{2}$, about -0.064582 a.u., which is shown in table 2 and figure $4 \mathrm{~b}$. It is clear that the graphene@ $\mathrm{Al}$ behave as charge donor while interacting with the $\mathrm{NO}_{2}$.

For $\mathrm{CCl}_{2} \mathrm{~F}_{2}$ adsorption on $\mathrm{PG}$, the most energetically favourable configuration is similar to the graphene_ $\mathrm{CCl}_{4}$ and graphene_ $\mathrm{CH}_{4}$. In this configuration, the $\mathrm{CCl}_{2} \mathrm{~F}_{2}$ is adsorbed to $\mathrm{PG}$ with one $\mathrm{F}$ atom of $\mathrm{CCl}_{2} \mathrm{~F}_{2}$ pointing downwards as shown in figure $2 \mathrm{~h}$ and table 1 . The adsorption of $\mathrm{CCl}_{2} \mathrm{~F}_{2}$ on $\mathrm{PG}$ shows interaction with the adsorption energy of $-0.119 \mathrm{eV}$ with molecule sheet distance of $3.355 \AA$, indicating the weak physisorption nature. The calculated charge transfer from $\mathrm{CCl}_{2} \mathrm{~F}_{2}$ is only 0.004 a.u. Therefore, the $\mathrm{PG}$ is not senstive to the $\mathrm{CCl}_{2} \mathrm{~F}_{2}$. When the $\mathrm{CCl}_{2} \mathrm{~F}_{2}$ is adsorbed on Al-doped graphene, both florine atoms of $\mathrm{CCl}_{2} \mathrm{~F}_{2}$ get close to the grapehe@Al. In this configuration, the adsorption energy, molecule sheet distance and charge transfer is $-1.361 \mathrm{eV}$,
$3.956 \AA$ and 0.02 a.u., respectively, which indicates that interaction is weak in nature due to very small charge transfer (as shown in figure $4 \mathrm{~b}$ and table 2).

In the graphene_SO $\mathrm{SO}_{2}$ complex structure, the $\mathrm{S}$ atom of $\mathrm{SO}_{2}$ is close to the $\mathrm{C}$ atom of PG. The adsorption energy $E_{\text {ad }}$ and shortest distance from $\mathrm{PG}$ to the $\mathrm{S}$ atom of $\mathrm{SO}_{2}$ are $-0.279 \mathrm{eV}$ and $3.578 \AA$, respectively, suggesting a weak interaction between the $\mathrm{SO}_{2}$ and $\mathrm{PG}$ (as shown in figure $4 \mathrm{c}, \mathrm{d}$ and table 1). However, there is no change in the electronic properties of $\mathrm{PG}$ due to the low charge transfer, about 0.025 a.u. from $\mathrm{SO}_{2}$ to the $\mathrm{PG}$. Therefore, $\mathrm{PG}$ is not sensitive to the $\mathrm{SO}_{2}$ molecule. As shown in figure $3 \mathrm{i}$, the $\mathrm{SO}_{2}$ is adsorbed on Al-doped graphene, the $\mathrm{S}$ atom of $\mathrm{SO}_{2}$ gets close to the graphene@ $\mathrm{Al}$ because the $\mathrm{Al}$ atom is negatively charged and $\mathrm{S}$ atom is positively charged. The charge on $\mathrm{Al}, \mathrm{S}, \mathrm{O}(98)$ and $\mathrm{O}(99)$ are $-0.283,0.796,-0.373$ and -0.378 a.u., respectively, indicating that $\mathrm{Al}$ atom repels both oxygen atoms but attracts the $\mathrm{S}$ atom because $\mathrm{S}$ atom becomes more positively charged. In this complex structure, the adsorption energy and molecule sheet distance between $\mathrm{S}$ and $\mathrm{Al}$ is $-1.608 \mathrm{eV}$ and $3.579 \AA$ as shown in figure $3 \mathrm{i}$ and table 2 . However, the charge transfer is very low from $\mathrm{SO}_{2}$ to grahene@ $\mathrm{Al}$, which is about 0.045 a.u.

For $\mathrm{CF}_{4}$ adsorption on $\mathrm{PG}$, the most energetically favourable configuration is similar to the graphene_CCl4 and graphene_CH4. In this configuration, the $\mathrm{CF}_{4}$ is adsorbed to $\mathrm{PG}$ with one $\mathrm{F}$ atom of $\mathrm{CF}_{4}$ pointing downward as shown in figure $2 \mathrm{j}$ and table 1 . The adsorption of $\mathrm{CF}_{4}$ on $\mathrm{PG}$ is the non-covalent interaction with the adsorption energy of $-0.150 \mathrm{eV}$ and the molecule sheet distance of $3.404 \AA$, indicating the weak physisorption. The calculated charge transfer from $\mathrm{CF}_{4}$ is only 0.055 a.u. Therefore, $\mathrm{PG}$ is not senstive to $\mathrm{CF}_{4}$. When $\mathrm{CF}_{4}$ is adsorbed on $\mathrm{Al}$-doped graphene, one florine atom of $\mathrm{CF}_{4}$ gets close to graphene@ Al. In this configuration, the adsorption energy, molecule sheet distance and charge transfer is $-1.354 \mathrm{eV}, 3.404 \AA$ and 0.135 a.u., respectively. Therefore, we can say that graphene@Al is more sensitive than PG towards the $\mathrm{CF}_{4}$ molecule (figure $3 \mathrm{j}$ and table 2). In this complex, graphene@ Al acts as a charge acceptor.

The $\mathrm{H}_{2}$ molecule was initially placed parallel to the graphene. After full relaxation, a configuration with the adsorbed $\mathrm{H}_{2}$ axis gets aligned almost parallel to the graphene surface along the axis of two opposite $\mathrm{C}$ atoms of the $6 \mathrm{MR}$ and was found to be the most stable one for the PG. The adsorption energy of this system is $-0.013 \mathrm{eV}$ and the molecule sheet distance is $3.946 \AA$ as shown in figure $3 \mathrm{k}$ and table 1 , which are suggesting weak interaction between $\mathrm{H}_{2}$ and graphene. The charge transfer between $\mathrm{H}_{2}$ and graphene is 0.0007 a.u. In this configuration, $\mathrm{PG}$ is not sensitive towards the $\mathrm{H}_{2}$ molecule. When adsorbed on graphene @ $\mathrm{Al}, \mathrm{H}_{2}$ is oriented perpendicular to the Al-doped graphene plane, with one $\mathrm{H}(97)$ atom close to the graphene@Al. In this complex structure, the adsorption energy, molecule sheet distance and charge transfer are $-1.637 \mathrm{eV}, 6.306 \AA$ and 0.001 a.u., respectively. Interestingly, the graphene@ Al has more adsorption energy than PG. 
As shown in figure 21, the most stable configuration of $\mathrm{N}_{2} \mathrm{O}$ adsorbed on PG (graphene_ $\mathrm{N}_{2} \mathrm{O}$ ) is similar to graphene_ $\mathrm{CO}_{2}$, where the gas molecule axis is aligned parallel to the graphene plane along the axis of two opposite $\mathrm{C}$ atoms of the 6MR. However, the $\mathrm{N}_{2} \mathrm{O}$ in graphene_ $\mathrm{N}_{2} \mathrm{O}$ is located above the centre of the $6 \mathrm{MR}$. The calculated adsorption energy and molecule sheet distance are $0.123 \mathrm{eV}$ and $3.634 \AA$, respectively. The low adsorption energy and long molecule sheet distance are suggesting weak physisorption. However, it is found that the interaction is significantly improved when a $\mathrm{C}$ atom in the $\mathrm{PG}$ is replaced by an $\mathrm{Al}$ atom. Figure 31 shows the most stable configuration of $\mathrm{N}_{2} \mathrm{O}$ adsorbed on graphene@ $\mathrm{Al}$, where the oxygen atom of $\mathrm{N}_{2} \mathrm{O}$ is close to the $\mathrm{Al}$ atom of graphene@ $\mathrm{Al}$. The adsorption energy $E_{\mathrm{ad}}$ for graphene@ $\mathrm{Al} \mathrm{N}_{2} \mathrm{O}$ is $-1.409 \mathrm{eV}$, which is clearly higher than that for graphene_ $\mathrm{N}_{2} \mathrm{O}$. The interaction distance between the $\mathrm{N}_{2} \mathrm{O}$ molecule and the graphene@ $\mathrm{Al}$ decreases to $2.163 \AA$, which indicates strong interaction. The charge transfer from $\mathrm{N}_{2} \mathrm{O}$ to the graphene is 0.518 a.u. The large transferred charge suggests that the local electronic properties of graphene@ $\mathrm{Al}$ is remarkably changed due to the adsorption of $\mathrm{N}_{2} \mathrm{O}$ on graphene@Al.

The above mentioned results suggest that PG has weak interaction towards all gas molecules. Introducing dopants like $\mathrm{Al}$ atom into the graphene significantly increases the molecule-graphene interaction. The order of adsorption energy for small gas molecule complexes is $\mathrm{NO}_{2}>\mathrm{CCl}_{4}>\mathrm{SO}_{2}$ $>\mathrm{CF}_{4}>\mathrm{NH}_{3}>\mathrm{N}_{2} \mathrm{O}>\mathrm{CO}_{2}>\mathrm{CCl}_{2} \mathrm{~F}_{2}>\mathrm{CO}>\mathrm{N}_{2}>\mathrm{CH}_{4}>\mathrm{H}_{2}$ with PG and $\mathrm{NO}_{2}>\mathrm{NH}_{3}>\mathrm{CO}_{2}>\mathrm{H}_{2}>\mathrm{SO}_{2}>\mathrm{N}_{2} \mathrm{O}>\mathrm{CCl}_{2} \mathrm{~F}_{2}>$ $\mathrm{CF}_{4}>\mathrm{CCl}_{4}>\mathrm{N}_{2}>\mathrm{CO}>\mathrm{CH}_{4}$ with Al-doped graphene. Interestingly, our results predicted that Al-doped graphene are more suitable for gas sensing applications, since they have stronger interactions with all small gas molecules than PG. The Al-doped graphene particularly shows the highest sensitivity towards $\mathrm{NO}_{2}, \mathrm{NH}_{3}$ and $\mathrm{CO}_{2}$.

\subsection{HOMO-LUMO energy gap}

The primary requisite for a material to perform as a sensor is to undergo a change in its physical property on interacting with an analyte. Such changes can be monitored and recorded to determine the presence of the analyte. The HOMO-LUMO energy gap is defined as the difference between lowest unoccupied molecular orbital and highest occupied molecular orbital. It is the electronic property of any molecular system, which is helpful to design new materials. In order to notice such a depiction in the case of carbon materials, we have calculated the HOMO-LUMO energy gap of the PG and Al-doped graphene in the free state and in the small gas molecule complexes. In general, in the case of $\mathrm{X}-\pi$ complexes, the HOMO-LUMO energy gap of single-walled carbon nanotube (SWCNT) varies with orientation of small gas molecules on the PG and Al-doped graphene. It has been shown that the energy gap of PG is not significant but when the gas molecules is adsorbed on graphene@ $\mathrm{Al}$ then significant changes in HOMO-LUMO energy gap is observed (as shown in table 2). Therefore, we can say that the variation in HOMO-LUMO energy gap of the graphene upon binding with the various small gas molecules is significant.

\section{Conclusion}

The adsorption energy of various small gas molecules such as $\mathrm{CCl}_{4}, \mathrm{CH}_{4}, \mathrm{NH}_{3}, \mathrm{CO}_{2}, \mathrm{CO}, \mathrm{NO}_{2}, \mathrm{CCl}_{2} \mathrm{~F}_{2}, \mathrm{SO}_{2}, \mathrm{CF}_{4}$ and $\mathrm{N}_{2} \mathrm{O}$ with the pure and Al-doped graphene (graphene@ $\mathrm{Al}$ ) has been comprehensively analysed. These calculations reveal that the adsorption energy has preferences of small gas molecules with the doping in graphene as well as molecule sheet distance. It can be seen from the results that the adsorption energy of these gas molecules is higher for the Al-doped graphene than for the PG. PG shows weak sensitivity to all gas molecules. Compared with PG, graphene@ Al has a higher chemical reactivity towards all gas molecules due to the doping of $\mathrm{Al}$ atom and shows higher adsorption energy with $\mathrm{NO}_{2}, \mathrm{NH}_{3}$ and $\mathrm{CO}_{2}$. The strong interactions between graphene@Al and the adsorbed molecules induce dramatic changes in the electronic properties of graphene@Al and make graphene@ $\mathrm{Al}$ a promising candidate as gas sensing materials for $\mathrm{NO}_{2}, \mathrm{NH}_{3}$ and $\mathrm{CO}_{2}$. The Mulliken charge analysis reveals that the gas molecule acts as charge donor and acceptor in different configurations towards the pure and Al-doped graphene and influence the physical properties of carbon materials, which leads to the sensitivity. It has also been found that HOMO-LUMO energy gap of the CNT is always affected by the binding of the small gas molecules. Significant changes occur in the HOMO-LUMO energy gap on PG and graphene@ $\mathrm{Al}$ on interacting with gas molecules, which provides a handle to tune the electronic and conductivity properties of graphene through gas molecule complexation. These studies can also be applied to develop new carbon-based materials and sensing applications, focusing particularly on the binding mechanism of various gas molecules with graphene. Developing chemical and gas sensors based on carbon materials has become an area of significant research interest since the physical and electronic properties of these materials are vulnerable to external enviroment. It is to hope that our results would be helpful to develop novel carbon material-based gas sensors.

\section{Acknowledgements}

Dharmveer Singh and Asheesh Kumar acknowledge their financial support from the University Grants Commission (UGC), New Delhi.

\section{References}

[1] Hirsch A 2010 Nat. Mater. 9868

[2] Rao C N R, Sood A K, Subrahmanyam K S and Govindaraj A 2009 Angew. Chem. Int. Ed. 487752 
[3] Iijima S 1991 Nature 35456

[4] Liu J, Cui L and Losic D 2013 Acta Biomater. 99243

[5] Dinadayalane T C and Leszcznski J 2010 Struct. Chem. 21 1155

[6] Liang F and Chen B 2010 Curr. Med. Chem. 1710

[7] Zhu Y, Murali S, Cai W, Li X, Suk J W, Potts J R et al 2010 Adv. Mater. 223906

[8] Goldoni A, Larciprete R, Petaccia L and Lizzit S 2003 J. Am. Chem. Soc. 12511329

[9] Guo Z, Feng Y, He S, Qu M, Chen H, Liu H et al 2012 Adv. Mater. 25584

[10] Zhong J, Chiou J, Dong C, Glans P A, Pong W F, Chang C et al 2012 Appl. Phys. Lett. 100201605

[11] Umadevi D, Panigrahi S and Sastry G N 2014 Acc. Chem. Res. 472574

[12] Vijay D and Sastry G N 2010 Chem. Phys. Lett. 485235

[13] Shi G, Ding Y and Fang H 2012 J. Comput. Chem. 331328

[14] Grabowski S J and Lipkowski P 2011 J. Phys. Chem. A 115 4765

[15] Mahadevi A S and Sastry G N 2016 Chem. Rev. 1162775

[16] Charlier J C 2002 Acc. Chem. Res. 351063

[17] Huang P, Zhu H, Jing L, Zhao Y and Cao X 2011 ACS Nano 57945

[18] Dougherty D A 1996 Science 271163

[19] Kim S K, Hu S, Tarakeshwar P and Lee J Y 2000 Chem. Rev. 1004145

[20] Ready A S and Sastry G N 2005 J. Phys. Chem. A 1098893

[21] Schedin F, Geim A K, Morozov S V, Hill E W, Blake P, Katsnelson M I et al 2007 Nat. Mater. 6652

[22] Wang X, Sun G, Routh P, Kim D H, Huang W and Chen P 2014 Chem. Soc. Rev. 437067

[23] Lherbier A, Blase R X, Niquet Y, Triozon F and Roche S 2008 Phys. Rev. Lett. 101036808

[24] Lv Y-A, G-1 Zhuang G-I, Wang J-g, Jia Y-B and Xie Q 2011 Phys. Chem. Chem. Phys. 1312472

[25] Cho B, Yoon J, Hahm M G, Kim D H, Kim A R, Kahng Y H et al 2014 J. Mater. Chem. 25280

[26] Kong J, Franklin N, Zhou C, Chapline M, Peng S, Cho K et al 2000 Science 287622
[27] Umadevi D and Sastry G N 2011 J. Phys. Chem. C 1159656

[28] Umadevi D and Sastry G N 2011 J. Phys. Chem. Lett. 21572

[29] Chen W, Duan L and Zhu D 2007 Environ. Sci. Technol. 41 8295

[30] Panigrahi S, Bhattacharya S, Banerjee S and Bhattacharyya D 2012 J. Phys. Chem. C 1164374

[31] Roman T, Dino W A, Nakanishi H and Kasai H 2006 Eur. Phys. J. D. 38117

[32] Kumar A, Reddy A L M, Mukherjee A, Dubey M, Zhan X, Singh N et al 2011 ACS Nano 54345

[33] Reddy A L M, Srivastav A, Gowda S R, Gullapalli H, Dubey M and Ajayan P M 2010 ACS Nano 46337

[34] Rao J S, Zipse H and Sastry G N 2009 J. Phys. Chem. B 113 7225

[35] Sharma B, Rao J S and Sastry G N 2011 J. Phys. Chem. A 115 1971

[36] Mahadevi A S and Sastry G N 2011 J. Phys. Chem. B 115703

[37] Umadevi D and Sastry G N 2015 Phys. Chem. Chem. Phys. 17 30260

[38] Zhang Y H, Chen Y B, Zhou K C, Liu C H, Zeng J, Zhang H L et al 2009 Nanotechnology 20185504

[39] Zou Y, Li F, Zhu Z H, Zhao M W, Xu X G and Su X Y 2011 Eur. Phys. B 81475

[40] Becke A D 1993 J. Chem. Phys. 985648

[41] Ditchfield R, Hehre W J and Pople J A 1971 J. Chem. Phys. 54 724

[42] Frisch M J, Trucks G W, Schlegel H B, Scuseria G E, Robb M A, Cheeseman J R et al 2010 Gaussian Inc., Wallingford, CT

[43] Zhao Y and Truhlar D G 2008 Theor. Chem. Acc. 120215

[44] Petersson G A, Bennett A, Tensfeldt T G, Al-Laham M A, Shirley W A and Mantzaris J 1988 J. Chem. Phys. 892193

[45] Petersson G A and Al-Laham M A 1991 J. Chem. Phys. 94 6081

[46] Frisch M J, Pople J A and Binkley J S 1984 J. Chem. Phys. 80 3265

[47] Dai J Y and Yuan J M 2010 Phys. Rev. B 81165414

[48] Bai L and Zhou Z 2007 Carbon 452105

[49] Charles W, Bauschlicher J and Ricca A 2004 Phys. Rev. B 70 115409 